\title{
ASSESSMENT OF SERUM VITAMIN D LEVELS IN YOUNG ADULTS AND CORRELATION OF VITAMIN D DEFICIENCY AND GINGIVITIS
}

\author{
Rania Farouk Abdulmaguid*, Salah Hamed Sherif** and Hakem H. Elsayed***
}

\begin{abstract}
Background: Assessment of vitamin D levels in serum of dental students of faculty of dentistry MSA University, with examination of plaque index, gingival index and bleeding on probing for each student.
\end{abstract}

Aim: The aim of the present study is to study the prevalence of vitamin D deficiency among dental students and to find out if any correlation is present between the deficiency, if present, and gingival inflammation.

Material and Methods: Forty-seven students were randomly selected from the dental students in the final year from MSA University, assessment for serum vitamin D and gingival inflammation was done for all the students.

Results: All the assessed students were suffering from vitamin D deficiency, the severity was variable from severe to moderate, all students were also suffering from gingivitis despite their good oral hygiene (PI)

Conclusion: There was a correlation between serum vitamin D level and gingivitis which was revealed as an inverse relationship between level of vitamin D and both of gingival index and bleeding on probing.

\section{INTRODUCTION}

During the last decade, there has been an increasing interest in the beneficial effects of vitamin $\mathrm{D}$ on a wide range of health outcomes. It is well-known that this nutrient plays an important role in bone mineralization and other metabolic processes in the human body such as calcium (Ca) and phosphate homeostasis and skeletal growth ${ }^{(1)}$. Vitamin D is a fat-soluble vitamin that is metabolized by the body by either sun (ultraviolet light) exposure or dietary intake. There are 2 molecules that make up vitamin $\mathrm{D}$ : ergocalciferol $\left(\mathrm{D}_{2}\right)$ and cholecalciferol (D3) ${ }^{(2)}$. Ultraviolet B (UVB) radiation is absorbed by the skin and converts 7-dehydrocholesterol to vitamin $\mathrm{D}_{3}{ }^{(3)}$.

* Lecturer at Oral Medicine and Periodontology Department Faculty of Dentistry MSA University.

** Dean Faculty of Oral and Dental Medicine MSA University

*** Head of Oral Medicine \& Periodontology Dept. Faculty of Dentistry. MSA University 
Serum 25-hydroxyvitamin D [25(OH)D] concentration is the parameter of choice for the assessment of vitamin D status; as it reflects vitamin D exposure, incorporating endogenous synthesis from solar exposure, dietary intake from foods, fortified products, and/or supplements ${ }^{(4)}$. Although there are some areas of dispute in relation to vitamin $\mathrm{D}$ requirements and the impact of vitamin D intake and status on many aspects of human health, there is a general agreement that prevention of vitamin D deficiency and insufficiency should be considered as a public health priority ${ }^{(5)}$. Vitamin $\mathrm{D}_{3}$ then goes into the capillary bed, where it binds to vitamin $\mathrm{D}$ binding protein (DBP). Vitamin $\mathrm{D}_{2}$ and vitamin $\mathrm{D}_{3}$ are also ingested through the diet from fortified milk, fatty fish (salmon), and fortified cereals. Once ingested, they are incorporated into chylomicrons. The chylomicrons are transported through the lymphatic system and then are released into venous circulation, where vitamin $\mathrm{D}$ is bound to lipoproteins and DBP ${ }^{(6)}$. Both vitamin D from the sun and diet then enter the liver and are converted to 25-hydroxyvitamin $\mathrm{D}\left[25(\mathrm{OH}) \mathrm{D}_{3}\right]$ (calcidiol); $25(\mathrm{OH}) \mathrm{D} 3$ (calcidiol) is the major circulating form of vitamin $\mathrm{D}$ and is used to determine vitamin $\mathrm{D}$ status. To become biologically active, it requires additional hydroxylation in the kidneys to form active 1,25-hydroxyvitamin D [1,25(OH)2D] (calcitriol); however, 1,25(OH)2D is not used to determine vitamin $\mathrm{D}$ status because it circulates at 1000 times less concentration than $25(\mathrm{OH}) \mathrm{D}_{3}$ and it has a half-life of 6 hours in comparison to 2 weeks for $25(\mathrm{OH}) \mathrm{D}_{3}{ }^{(6)}$.

Furthermore, it plays a crucial role in calcium homeostasis and bone mineral metabolism. Vitamin $\mathrm{D}$ endocrine system is also known to support a wide range of fundamental biological functions in cell differentiation, inhibition of cell growth as well as innate and adaptive immunity ${ }^{(7-9)}$. In adults, chronic vitamin D deficiency leads to osteoporosis, osteomalacia, muscle weakness and increased risk of falls and fractures. Insufficient vitamin D intake and low blood levels of vitamin D metabolites are related to increased incidence of several autoimmune diseases involving the $\mathrm{T}$ helper type 1 lymphocyte, including multiple sclerosis, rheumatoid arthritis, type 1 diabetes, systemic lupus erythematosus and psoriasis ${ }^{(10)}$.

Vitamin D deficiency is pandemic, yet it is the most under-diagnosed and under-treated nutritional deficiency in the world ${ }^{(11-13)}$. Vitamin D deficiency is common in individuals irrespective of their age, gender, race and geography. Eruption of permanent teeth may be delayed, and there may be enamel defects ranging from pitting to complete absence of enamel (14). Vitamin D and calcium deficiency have been found to result in generalized jaw bone resorption and loss of PDL ${ }^{(14)}$. Enamel hypoplasia is a common sign associated with vitamin $\mathrm{D}$ deficiency during mineralization and maturation of tooth enamel prior to eruption. Such hypoplastic teeth have increased susceptibility to dental caries $^{(15)}$. The first dental change seen when vitamin D deficiency occurs during tooth development and calcification is hypoplasia (incomplete development of the enamel and dentin). As a result of a lack of vitamin $\mathrm{D}$, the enamel calcifies poorly and may in some areas fail to form. In the dentin, spaces that represent uncalcified dentin matrix occur. The appearance of a calciotraumatic line in the dentin is the earliest sign of an acute deficiency of vitamin $\mathrm{D}^{(16)}$. More recent studies showed significant associations between periodontal health and intake of vitamin D and calcium and that dietary supplementation with calcium and vitamin D may improve periodontal health, increase bone mineral density in the mandible and inhibit alveolar bone resorption ${ }^{(16)}$. Garcia et al. ${ }^{(17)}$ reported that calcium and vitamin D supplementation may reduce the severity of periodontal disease if used at doses higher than 800-1,000 IU daily. It was also observed that vitamin $\mathrm{D}$, in addition to its role in bone and calcium homeostasis, acts as an anti-inflammatory agent because it inhibits immune cell cytokine 
expression and causes monocyte/ macrophages to secrete molecules that have a strong antibiotic effect.

Some studies have suggested that vitamin D may have valuable effect because of its anti-inflammatory effects ${ }^{(18-20)}$. However, a study on association between serum vitamin $\mathrm{D}$ levels and periodontal disease as well as tooth loss in US population proved to be positive with high prevalence associated with deficiency in Vitamin $\mathrm{D}^{(21)}$. In a study by Boston University study evaluation of the association between the serum concentration of 25-hydroxyvitamin D and gingival inflammation was assessed and concluded that Vitamin D could reduce the susceptibility to gingival inflammation by its anti-inflammatory effect through inhibiting antigen induced $\mathrm{T}$ cell proliferation and cytokine production $^{(22)}$.

\section{MATERIALS AND METHODS}

Forty-seven dental students (twenty-eight males, and nineteen females) were randomly selected from the final year school students in Faculty of Dentistry MSA University. All the students were free of systemic disease and they were willing to participate in the study and were not taking any supplements or medications. A thorough periodontal examination was done for each of them where, gingival index, plaque index (according to Loe and Silness) ${ }^{(23)}$ and bleeding on probing (according to Ainamo and Bay) ${ }^{(24)}$ were done in the following manner:

- All the measurements were taken on the upper and lower anterior teeth.

- When calculating the gingival index for each candidate, two points were taken for each tooth, then all the readings were summed up and divided by the number of teeth accessed.

- When calculating the plaque index for each candidate, two points were taken for each tooth, then all the readings were summed up and divided by the number of teeth accessed.
- When calculating bleeding on probing for each candidate, each tooth present was gently probed with a periodontal probe at six sites (mesial, mid, and distal on both buccal and lingual surfaces): bleeding was scored as present or absent and the number of sites where bleeding was present was recorded. The number of sites then was divided by the total number of available sites in the mouth. The number of bleeding points on each tooth were summed for all the teeth and then divided by the number of the teeth accessed.

- Serum vitamin D was assessed for all students in the same lab for consistency and standardization.

\section{RESULTS}

This study comprised forty-seven student candidates, twenty-eight males and nineteen females with a mean age of $23.57 \pm 1.99$ and a range of 31 to 22 years (males: $23.71 \pm 1.84$; females: $23.37 \pm 2.22$ ). The mean vitamin D level for the studied candidates was $14.05 \pm 5.35$ with a range of 30 to 5.89 (males: $15.40 \pm 4.77$; females: $12.05 \pm 5.66)$. The mean gingival index was $2.55 \pm 0.91$ with a range of 3.9 to 0.5 (males: $2.32 \pm 0.9$; females: $2.89 \pm 0.83$ ). The mean plaque index was $1.68 \pm 0.98$ with a range of 4.2 to 0 (males: $1.79 \pm 1.11$; females: $1.53 \pm 0.77$ ). The mean bleeding on probing was $3.43 \pm 1.29$ with a range of 6 to 0 (males: $3.17 \pm 1.40$; females: $3.82 \pm 1.03)$.

The study correlated the levels of vitamin D to the clinical parameters using Spearman rank correlation. The outcomes of these correlations were as follows:

\section{Vitamin D vs. Gingival Index}

Spearman $\mathrm{r}$ equaled -0.3998 with a $95 \%$ confidence interval or -0.6217 to -0.1186 , and a $p$ value of 0.0054 which is considered very significant (figure 1). There was an inverse association between serum concentrations of $25(\mathrm{OH}) \mathrm{D}$ and chronic gingivitis. 


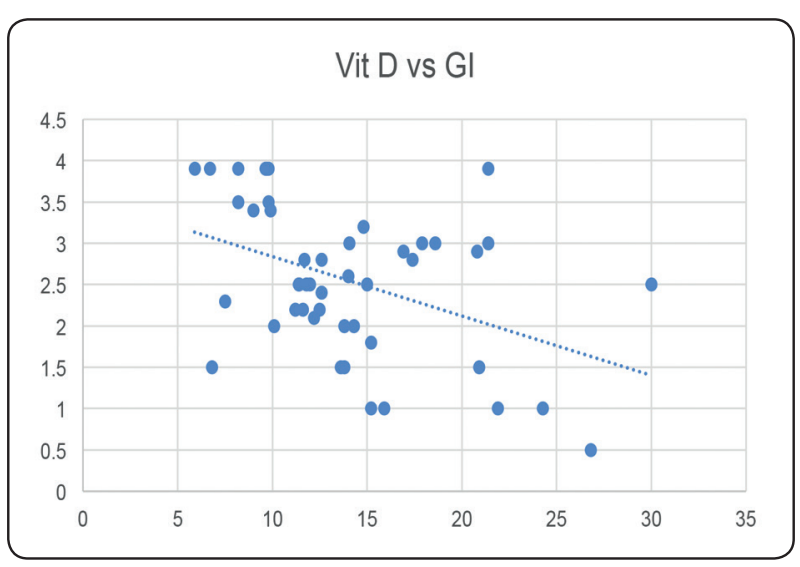

Fig. (1) Scatter diagram and trend tendency of Vit. D and GI

\section{Vitamin D vs. Plaque Index}

Spearman $\mathrm{r}$ equaled 0.1619 with a 95\% confidence interval or -0.14 to 0.4363 , and a $p$ value of 0.2769 which is considered non-significant.

\section{Vitamin D vs. Bleeding on Probing}

Spearman $\mathrm{r}$ equaled - 0.4843 with a $95 \%$ confidence interval or -0.6820 to -0.2206 , and a $p$ value of 0.0006 which is considered very significant (figure 2). There was an inverse association between serum concentrations of $25(\mathrm{OH}) \mathrm{D}$ and bleeding on probing (figure 3 ).

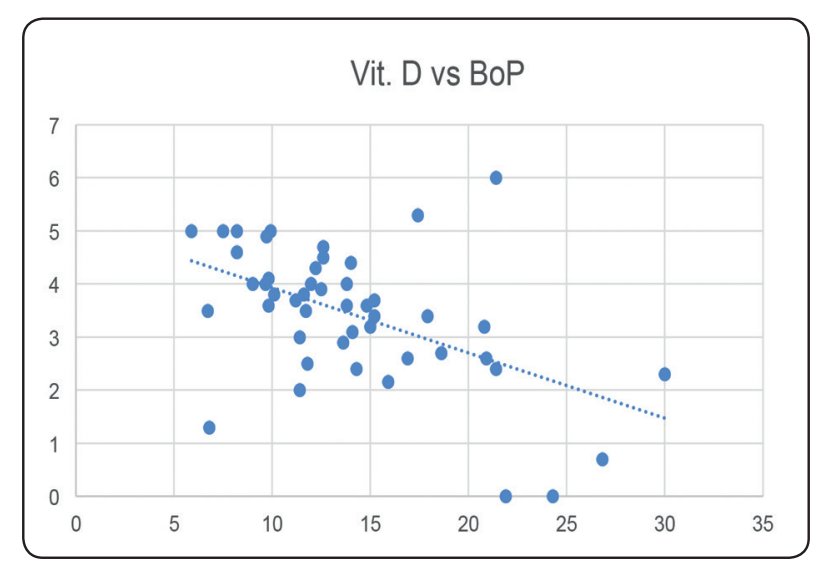

Fig. (2) Scatter diagram and trend tendency of Vit. D and BoP

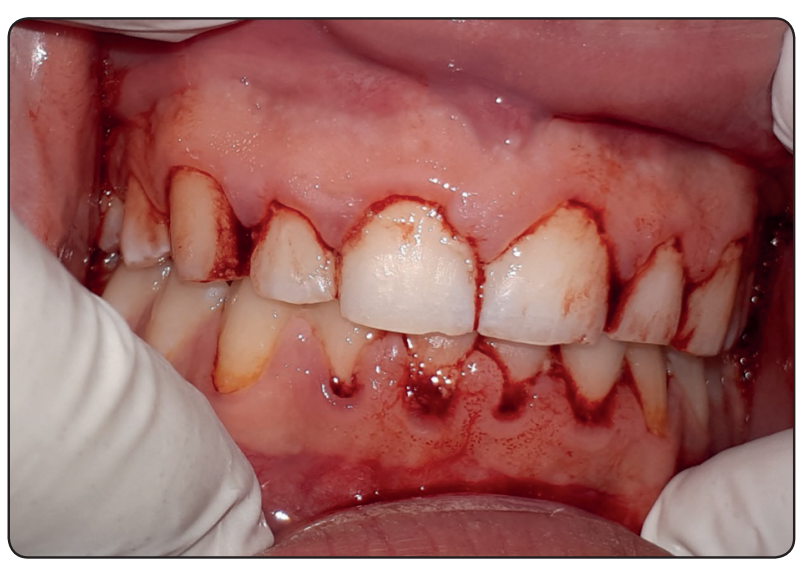

Fig. (3) Case of severe Vit. D deficiency following clinical examination

\section{DISCUSSION}

The present study revealed an inverse relationship between serum level of Vitamin D and both of Gingival index and bleeding on probing, though the plaque index showed no significant difference and was with a mean of $1.68 \pm 0.98$.

The study results are in agreement with the earlier study done by Dietrich et al. ${ }^{(25)}$ Who found a strong negative association between serum concentrations of $25(\mathrm{OH}) \mathrm{D}$ and prevalence of bleeding on probing. Compared with the lowest 25(OH)D quintile, sites in subjects in the highest $25(\mathrm{OH}) \mathrm{D}$ quintile had $20 \%$ (95\% CI: $8 \%, 31 \%$ ) lower odds of bleeding on probing. An increase in serum concentration of $25(\mathrm{OH}) \mathrm{D}$ of $30 \mathrm{ng} / \mathrm{ml}$ was associated with sites having 10\% (95\% CI: 5\%, 14\%) lower odds for bleeding. Therefore, we could say that serum vitamin $\mathrm{D}$ would be the best predictor of gingival status ${ }^{(26)}$.

Many studies ${ }^{(27,28)}$ suggested that vitamin D and/ or calcium intake results in reduced alveolar bone loss, gingival inflammation and/or attachment loss. Specifically, Dietrich et al. ${ }^{(27)}$ used the NHANES III data to examine the association between serum vitamin D levels and attachment loss and found an inverse relationship: the lower the levels of vitamin $\mathrm{D}$, the more attachment loss that was noted, 
with the association being independent of factors such as smoking habits and diabetes. They attributed this inverse relationship to the anti-inflammatory effects of vitamin D. A separate analysis of the NHANES III data revealed that individuals with the highest $25(\mathrm{OH}) \mathrm{D}$ levels experienced $20 \%$ less bleeding on probing than did those with the lowest levels, suggesting that vitamin D may reduce the risk of gingival inflammation by exerting antiinflammatory effects ${ }^{(29)}$.

A potential role of vitamin $\mathrm{D}$ in periodontal health is also supported by the findings that polymorphisms of the VDR gene are associated with periodontitis, alveolar bone loss, clinical attachment loss and/or tooth loss ${ }^{(30-32)}$. A recent study by Boggess et al. ${ }^{(33)}$ supports the evidence that vitamin $\mathrm{D}$ is important in maintaining periodontal health. They reported that insufficient maternal vitamin D status is a risk factor for moderate to severe periodontal disease during pregnancy. Pregnant women with moderate to severe periodontal disease had lower serum 25(OH)D levels and were more likely to have a $25(\mathrm{OH}) \mathrm{D}$ level of $<75 \mathrm{nM}$ compared with periodontally healthy women. More recently, Alshouibi et al. ${ }^{(34)}$ examined the association between total vitamin D intake and periodontal health in older men. They found that the total vitamin D intake was inversely associated with the presence of severe periodontitis and moderate to severe bone loss. In addition, a daily intake of $\geq 800 \mathrm{IU} / \mathrm{d}$ seemed to be the threshold for preventing moderate to severe periodontitis. Several studies showed significant associations between periodontal health and intake of vitamin D and calcium and that dietary supplementation with calcium and vitamin D may improve periodontal health, increase bone mineral density in the mandible and inhibit alveolar bone resorption ${ }^{(29,35)}$.

Similarly, periodontal maintenance patients taking calcium and vitamin D supplements had better periodontal health (shallower probing depths, fewer bleeding sites, lower gingival index values, fewer furcation involvements, less attachment loss and less alveolar crest height loss) compared with those who did not ${ }^{(17)}$.

In a previous study, it was found that there was an inverse association between serum concentrations of $25(\mathrm{OH}) \mathrm{D}$ and chronic gingivitis as measured by Loe and Silness gingival index among participants who never smoked, aged 18 to 65 years ${ }^{(36)}$.

In a cross-sectional study of 116 subjects, serum concentrations of $25(\mathrm{OH}) \mathrm{D}$ were negatively correlated with serum concentrations of C-reactive protein. In a subsample of 24 patients from that study, vitamin D supplementation significantly reduced serum concentrations of C-reactive protein by $23 \%{ }^{(37)}$. This further demonstrates the inverse association of inflammation and serum 25(OH)D levels.

Serum tumor necrosis factor alpha concentrations were negatively correlated with serum vitamin D concentrations in healthy women in a study by Peterson, and Heffernan ${ }^{(38)}$.

\section{CONCLUSION AND RECOMMENDATIONS}

1. Based on the present study, which revealed the significant correlation between serum vitamin D deficiency and signs of gingivitis, it is essential to correct the level of vitamin D before starting periodontal treatment.

2. Due to the evident high prevalence of serum vitamin D deficiency among young adults, screening for vitamin $\mathrm{D}$ deficiency is advisable.

3. Patient education about the importance of vitamin D and the reasons of the deficiency should be discussed with each patient which is mainly owed to the limitation of vitamin D nutritional sources and the reduction of sun exposure.

4. Future studies are recommended to study the effect of the use of systemic and local vitamin D in adjunct to bone graft around dental implants. 


\section{REFERENCES}

1. Palacios, C. The role of nutrients in bone health, from A to Z. Crit. Rev. Food Sci. Nutr. 2006; 46: 621-628.

2. Giese KK. Do your patients have vitamin D deficiency? Clin Advisor.2007; 10: 70-75.

3. Holick MF. The role of vitamin D for bone health and fracture prevention. Curr Osteoporos Rep.2006; 4: 96-102.

4. Ross, A.C.; Manson, J.E.; Abrams, S.A.; Aloia, J.F.; Brannon, P.M.; Clinton, S.K.; Durazo-Arvizu, R.A.; Gallagher, J.C.; Gallo, R.L.; Jones, G.; et al. The 2011 report on dietary reference intakes for calcium and vitamin $\mathrm{D}$ from the Institute of Medicine: What clinicians need to know. J. Clin. Endocrinol. Metab. 2011; 96: 53-58.

5. Spiro, A.; Buttriss, J.L. Vitamin D: An overview of vitamin D status and intake in Europe. Nutr. Bull. BNF 2014; 39: 322-350.

6. Holick MF.The role of vitamin D for bone health and fracture prevention.Curr Osteoporos Rep.2006;4:96-102.

7. Harinarayan CV, Joshi SR. Vitamin D status in India - its implications and remedial measures. J Assoc Physicians India 2009; 57: 40-48.

8. Khan QJ, Fabian CJ. How I treat vitamin D deficiency. J Oncol Pract 2010; 6: 97-101.

9. Marwaha RK, Tandon N, Garg MK, Kanwar R, Narang A, Sastry A, et al. Vitamin D status in healthy Indians aged 50 years and above. J Assoc Physicians India 2011; 59: 706-709.

10. Pravina Shah, Sudhindra Kulkarni, S Narayani, Dhara Sureka, Supriya Dutta, Ankita S Vipat, Qayum Mukaddam, Kamlesh Patel, Sachin Suryawanshi, Manoj Naik, Manoj Prabhu. Prevalence Study of Vitamin D Deficiency and to Evaluate the Efficacy of Vitamin D3 Granules 60,000 IU Supplementation in Vitamin D Deficient Apparently Healthy Adults. Indian Journal of Clinical Practice, 2013; 23:

11. Van Schoor, N.M.; Lips, P. Worldwide Vitamin D Status. Best Pract. Res. Clin. Endocrinol. Metab. 2011, 25, 671-680.

12. Mithal,A.; Wahl, D.A.; Bonjour, J.P.; Burckhardt, P.; Dawson-Hughes, B.; Eisman, J.A.; El-Hajj Fuleihan, G.; Josse, R.G.; Lips, P.; Morales-Torres, J.; et al. Global vitamin D status and determinants of hypovitaminosis D. Osteoporos Int. 2009, 20, 1807-1820.
13. Van der Meer, I.M.; Middelkoop, B.J.; Boeke, A.J.; Lips, P. Prevalence of vitamin D deficiency among Turkish, Moroccan, Indian and sub-Sahara African populations in Europe and their countries of origin: An overview. Osteoporos. Int. 2011, 22, 1009-1021.

14. Dorsky R. Nutrition and oral health. Gen. Dent 2001; 49: 576-582.

15. Rosenfeld L. Vitamine-vitamin. The early years of discovery. Clin Chem 1997; 43: 680-85.

16. Anand N, Chandrasekaran S, Rajput N. Vitamin D and periodontal health: Current concepts. J Indian SocPeriodontol 2013; 17: 302-308.

17. Garcia MN, Hildebott CF, Civitelli R. One-year effect of vitamin $\mathrm{D}$ and calcium supplementation on chronic periodontitis. J Periodontol 2011; 82: 25-32.

18. Bhalla AK, Amento EP, Serog B, Glimcher LH. 5-Dihydroxyvitamin D3 inhibits antigen-induced T cell activation. J Immunol 1984; 133: 174854.

19. Rigby WF, Denome S, Fanger MW. Regulation of lymphokine production and human $\mathrm{T}$ lymphocyte activation by 5-dihydroxyvitamin D3. Specific inhibition at the level of messenger RNA. J Clin Invest 1987; 79: 165964.

20. Relationship between vitamin D receptor gene polymorphism and periodontitis. J Periodontal Res 2002; 37: 2637.

21. Dietrich T, Joshipura KJ, Dawson-Hughes B. et al. Association between serum concentrations of 25-hydroxyvitamin D3 and periodontal disease in the US population. Am J Clin Nutr 2004; 80: 108-113.

22. Dietrich Thomas, Nunn Martha, ans Heik Bess Dawson. Association between serum concentration of 25-hydroxyvitamin D and gingival inflammation. Am J Clin Nutr 2005; 82: 575-580.

23. Loe , H and Silness, J. periodontal disease in pregnancy .I. prevalence and severity, Acta Odont Scand 1963; 21: 533-551.

24. Ainamo,J. and Bay I. Problems and proposals for recording gingivitisand plaque, Int Dent J 1975; 25: 229-235.

25. Dietrich Thomas, Nunn Martha, ans Heik Bess Dawson. Association between serum concentration of 25-hydroxyvitamin D and gingival inflammation. Am J Clin Nutr 2005; 82: 575-580.

26. Heany RP. Long latency deficiency disease insights from calcium and vitamin D. Am J Cl Nut 2003; 78: 91-98. 
27. Dietrich T, Joshipura KJ, Dawson- Hughes B, BischoffFerrari HA. Association between serum concentrations of 25-hydroxyvitamin D3 and periodontal disease in the US population. Am J Clin Nutr 2004; 80: 108-113.

28. Hildebolt CF. Effect of vitamin D and calcium on periodontitis. J Periodontol 2005; 76: 1576-1587.

29. Dietrich T, Nunn M, Dawson-Hughes B, Bischoff-Ferrari HA. Association between serum concentrations of 25-hydroxyvitamin D and gingival inflammation. Am J Clin Nutr 2005; 82: 575-580.

30. Hennig BJ, Parkhill JM, Chapple IL, Heasman PA, Taylor JJ. Association of a vitamin D receptor gene polymorphism with localized early-onset periodontal diseases. J Periodontol 1999; 70: 1032-1038.

31. Inagaki K, Krall EA, Fleet JC, Garcia RI. Vitamin D receptor alleles, periodontal disease progression, and tooth loss in the VA dental longitudinal study. J Periodontol 2003; 74: 161-167.

32. Yoshie H, Kobayashi T, Tai H, GaliciaJC. The role of genetic polymorphisms in periodontitis. Periodontol 2000 2007; 43: 102-132.
33. Boggess KA, Espinola JA, Moss K, Beck J, Offenbacher S, Camargo CA Jr. Vitamin D status and periodontal disease among pregnant women. J Periodontol 2011; 82: 195-200.

34. Alshouibi EN, Kaye EK, Cabral HJ et al. Vitamin D and periodontal health in older men. J Dent Res 2013; 92: 689-693.

35. Nishida M, Grossi SG, Dunford RG, Ho AW, Trevisan M, Genco RJ. Calcium and the risk for periodontal disease. J Periodontol 2000; 71: 1057-1066.

36. Hiremath VP, Rao CB,Naik V, Prasad KVV. Multivariate analysis of association of serum vitamin D levels of $25(\mathrm{OH}) \mathrm{D}$ with marginal gingivitis. Int. J. Med. Public health 2012; $2: 50-55$.

37. TimmsPM, Mannan N, Hitman GA et al. Circulating MMP9, vitamin D and variation in the TIMP-1 response with VDR genotype: mechanisms for inflammatory damage in chronic disorders. Q J Med 2002; 95: 787-796.

38. Peterson CA, Heffernan ME. Serum tumor necrosis factor alpha concentrations are negatively correlated with serum $25(\mathrm{OH}) \mathrm{D}$ concentrations in healthy women. Journal of inflammation 2008; 5:10-15. 